\title{
The Kinematic Models of Crank with Angle and Time in Motor Housing Process
}

\author{
Run $\mathrm{Xu}^{*}$
}

Metallurgical Engineering Department, Gyeongsang National University, Gyeongnam, Chinju 52828, Korea

DOI: $10.36348 /$ sjet.2020.v05i11.013

| Received: 10.11 .2020 | Accepted: 22.11.2020 | Published: 25.11 .2020

*Corresponding author: Run $\mathrm{Xu}$

Abstract

With regards to the assembly line of cost control of Dechang (HK) company, the motor housing's cost control of process will be necessarily respected. Because the supply quantity is big in a machine the price of motor housing is small, so that the cost control of automatic production line is significant with modeling. It is found that the control of equipment includes in shaft and crank linkage for benefit which also needs to be controlled in detail. For the sake of benefits can we fundamentally resolve the main problem of high cost process.

Keywords: Automatic production line; crank linkage; motor; motor housing; process modeling of cost control; kinematic \& dynamics control.

Copyright (C) 2020 The Author(s): This is an open-access article distributed under the terms of the Creative Commons Attribution 4.0 International License (CC BY-NC 4.0) which permits unrestricted use, distribution, and reproduction in any medium for non-commercial use provided the original author and source are credited.

\section{INTRODUCTION}

Motor housing can be used in assembly line production, because of its thin thickness, can work in the machine line.In the process of stamping, the coil steel plate and the punch press are connected into four working procedures, and three deep drawing operations in a short time to complete the continuous processing of the motor shell. They produce a lot of products in a certain amount of time. Since the production line is an automatic feed punch, it is difficult to control the cost. So we should focus on this cost issue and work for scientific management, networking and digital AI management. Due to excessive machine fatigue, and the processing speed is also fast, we need to carry out timely routine inspection of the machinery and equipment and focus on the hidden faults. This saves the cost of the trip to the manufacturer's personnel for repair due to machine failure and the loss caused by the shutdown of the machine. Because the load and frequency of the machine do not keep up with the loss caused by the fatigue condition under the load of the raw material and the die, the economic efficiency of the control structure of the crankshaft is an important factor in the automation industry. This paper discusses the crankshaft from the technical point of view of economic benefit [1-6] the crank is the most critical power mechanism, which turns the rotating motion of the spindle into the linear motion of the ramming motor shell and pushes and presses the thin steel plate. Therefore, the kinematics and dynamics of the crank are studied in order to optimize the crank parameters and save energy and high efficiency.

\section{Modeling \\ Dynamics of Motor Housing}

It is the process of three times of power in motor shell punching, as shown in Figure-3.

According to the concept of mechanical power,

Because $d P=F d l_{1} / \mathrm{t}-----(1)$

Here $\sigma=F / A=\frac{4 F}{\pi d_{1}^{2}}$------ $(2)$

It has $F=\sigma_{1} \pi d_{1}^{2} / 4$

According to the energy conservation law

$$
\begin{aligned}
& F=\frac{m v^{2}}{2 l_{1}} \\
& \text { Here } v=\frac{\pi d_{0} n}{90} \text {---------- }(5)
\end{aligned}
$$

$\mathrm{v}$ is crank's doing circulation movement at the diameter of $\rho_{\mathrm{z}} \mathrm{d}_{0}$ [2].

$$
\rho_{z}=\sqrt{\frac{J_{z}}{m}}
$$




$$
J_{z}=1 / 2 m R^{2}
$$

Substitute (6) into (7) it gains

$$
\rho_{z}=\frac{R}{\sqrt{2}} \text { ie } \rho_{z}=0.707
$$

Substitute (4) into above equation (5) it has

$$
F=\frac{m\left(\pi d_{0} n\right)^{2}}{16200 \times l_{1}}
$$

According to the defining with torque

$$
T=F d_{0}
$$

$\& T=9.55 \times 10^{5} \mathrm{P} / \mathrm{n}$

replace (11) with equation (10) and gains

$$
P=\frac{F d_{0} n}{9.55}
$$

Replace (12) with (9) and gains

$$
P=\frac{\pi n d_{0} \sigma d_{1}^{2}}{10.74}
$$

Here, $\mathrm{v} \mathrm{mm} / \mathrm{s}$ is the rotation speed of the driving wheel discussed above; $\mathrm{N} \mathrm{r} / \mathrm{min}$ is rotation; $\mathrm{P}$ $\mathrm{Kw}$ is the power; $\mathrm{T}$ is the torque $\mathrm{NKm}$. $\mathrm{F}_{1}$ is the force exerted by the punch at the first stroke; $\sigma_{1}$ is the impulse pressure. As shown in Table-1, ts is the time of the first punch, $\mathrm{m} ; \mathrm{D}_{1}$ is the diameter of the punch hole, which is the same as the diameter of the first punch shell. $\mathrm{L}_{1}$ is the punching length, which is the same as the first punching shell length $\mathrm{mm}$; $\mathrm{T}$ is the thickness. $\mathrm{D}_{0}$ is the final die diameter [1].

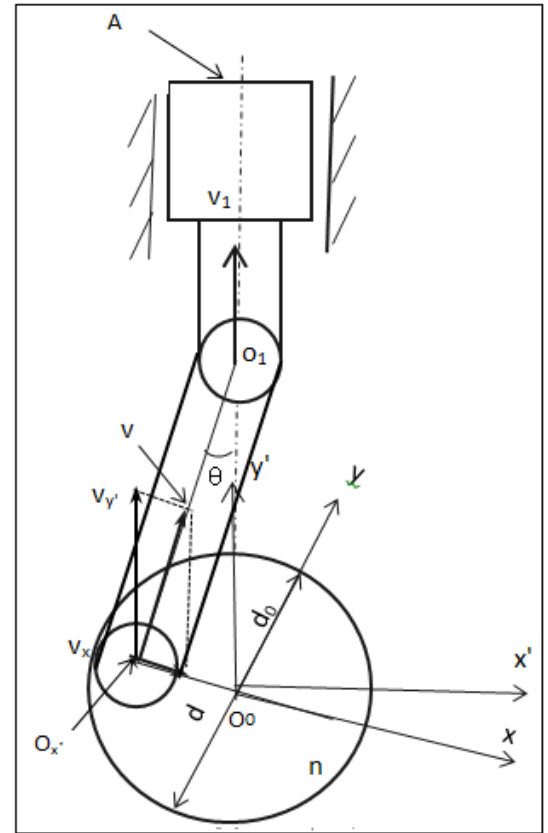

Fig-1: The kinematic of crankshaft linkage in the first motor housing process

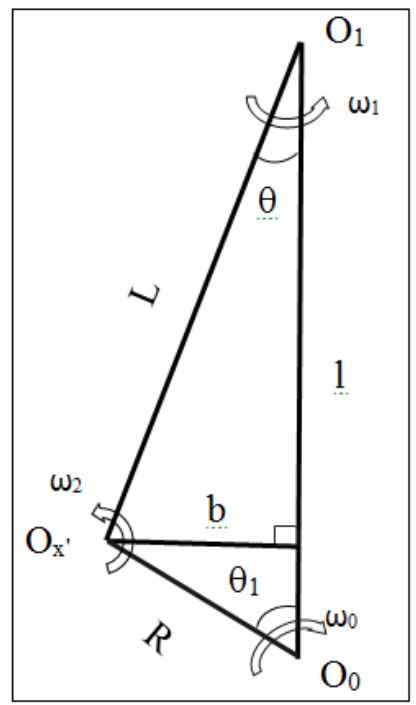

Fig-2: The kinematic of crankshaft linkage

\section{Kinematic Equations}

Figure-1 shows the kinematics diagram of crankshaft connecting rod device. The center of the coordinate system $x-y$ is $\mathrm{O}_{0}$, the crankshaft is the $\mathrm{OxO}_{0}$ part, and the $\mathrm{O}_{0}$ circular axis is the drive axis, which rotates $\mathrm{n}$ (RPM). Connect the die $\mathrm{O}_{1} \mathrm{~A}$ through $\mathrm{O}_{0} \mathrm{O} 1 . \mathrm{O}_{1} \mathrm{~A}$ in the $\mathrm{x}^{\prime}-\mathrm{y}^{\prime}$ coordinate system moves back and forth in a straight line in the $y^{\prime}$ direction of the orbit, moving at speed $\mathrm{v}_{1}$.In frame $\mathrm{x}$ prime minus $\mathrm{y}$ prime, $\mathrm{v}_{1}$ is equal to $\mathrm{v}$ sub $\mathrm{y}$ prime. Angle theta is the Angle between the die and the crank. $\mathrm{A}$ is the die acceleration; $\mathrm{D}$ is the length of the crank, that is, the diameter of the cyclotron; $\mathrm{D}_{0}$ is the diameter of the drive shaft. As shown in Figure-3, the stamping steel plate mold is $\mathrm{O}_{1} \mathrm{~A}$ in Figure-1. Where a is the first punch, $\mathrm{d} 1$ and 11 are the diameter and length of the first punch. B is the second punch, and $c$ is the fourth punch of cutting die. The third and fifth steps are omitted here. The third process is the final product size, which is similar to the second process, so it is omitted in this paper. The fifth step is to remove the shell to the designated point, as shown in the basket below, to facilitate storage and transportation. Assuming that all the forces are the same as F, it is only necessary to analyze the force on the first impact mold. The force analysis process is as follows.

The final member of the connecting rod structure by the crankshaft, namely the section $\mathrm{O}_{0} \mathrm{Ox}$ ' in the figure, has

$$
v_{0}=\pi d n
$$

According to lever structure principle in Figure-1

$$
v_{y^{\prime}}=\frac{v}{\cos \theta}
$$

Due to Figure-2 $v_{y^{\prime}}=v_{1}----$

$$
\text { So that } v_{1}=\frac{v}{\cos \theta}
$$


Here $\theta$ is included angle between mould and crank, so that

$$
v_{1}=\frac{v_{0}}{\cos \theta}
$$

Due to the stamping parts with ultimate velocity is zero

$$
\begin{aligned}
& v_{1}+a t=0-- \\
& \& d v_{1} / d t=-a
\end{aligned}
$$

a is acceleration of stamping parts.

Supposed that stamping time is below

$$
\mathrm{t}=0.3 \mathrm{~s}
$$

(20) take the place of (17) and gain

$$
a=\frac{-\pi d n}{t \cos \theta}
$$

\section{Equation of the included Angle between connecting} rod and center line

Figure-2 is a schematic diagram of crank linkage mechanism, and the parameter can be derived from the following. Set $\mathrm{Ox}{ }^{\prime} \mathrm{O}_{1}=\mathrm{L}, \mathrm{d}=\mathrm{R}, \mathrm{b}$ is perpendicular to the $\mathrm{L}$ and $\mathrm{O}_{1} \mathrm{O}_{0}=\mathrm{L}$

$$
\begin{aligned}
& l=R \cos \theta_{1}+L \cos \theta \\
& \& b=L \sin \theta=R \sin \theta_{1}
\end{aligned}
$$

Since law of cosines

$$
l^{2}=R^{2}+L^{2}-2 R L \cos \theta---
$$

According to Figure-2, when $\theta$ is maximum there is

$$
\theta=A \tan (R / L)
$$

According to above formula supposes that $\mathrm{R}=40 \mathrm{~mm}, \mathrm{~L}=120 \mathrm{~mm}$ and $\mathrm{l}=\mathrm{R}+\mathrm{L}-\Delta \mathrm{S}=160-30=130 \mathrm{~mm}$. This is the initial Angle of crank drive mould, $\Delta \mathrm{S}$ for slider here is about equal to $30 \mathrm{~mm}$ mold slip effectively.

Table-1: The $\boldsymbol{\theta m a x}$ and L \& R in crank
\begin{tabular}{|c|c|c|c|}
\hline No. & L $\mathbf{~ m m}$ & $\mathbf{R ~ m m}$ & $\boldsymbol{\Theta m a x}$ \\
\hline 1 & 70 & 120 & 30 \\
\hline 2 & 55 & 120 & 25 \\
\hline 3 & 40 & 120 & 18 \\
\hline 4 & 40 & 160 & 14 \\
\hline 5 & 55 & 160 & 19 \\
\hline 6 & 70 & 160 & 24 \\
\hline 7 & 70 & 130 & 28 \\
\hline 8 & 55 & 130 & 23 \\
\hline 9 & 40 & 130 & 17 \\
\hline 10 & 70 & 140 & 27 \\
\hline 11 & 55 & 140 & 21 \\
\hline 12 & 40 & 140 & 16 \\
\hline
\end{tabular}

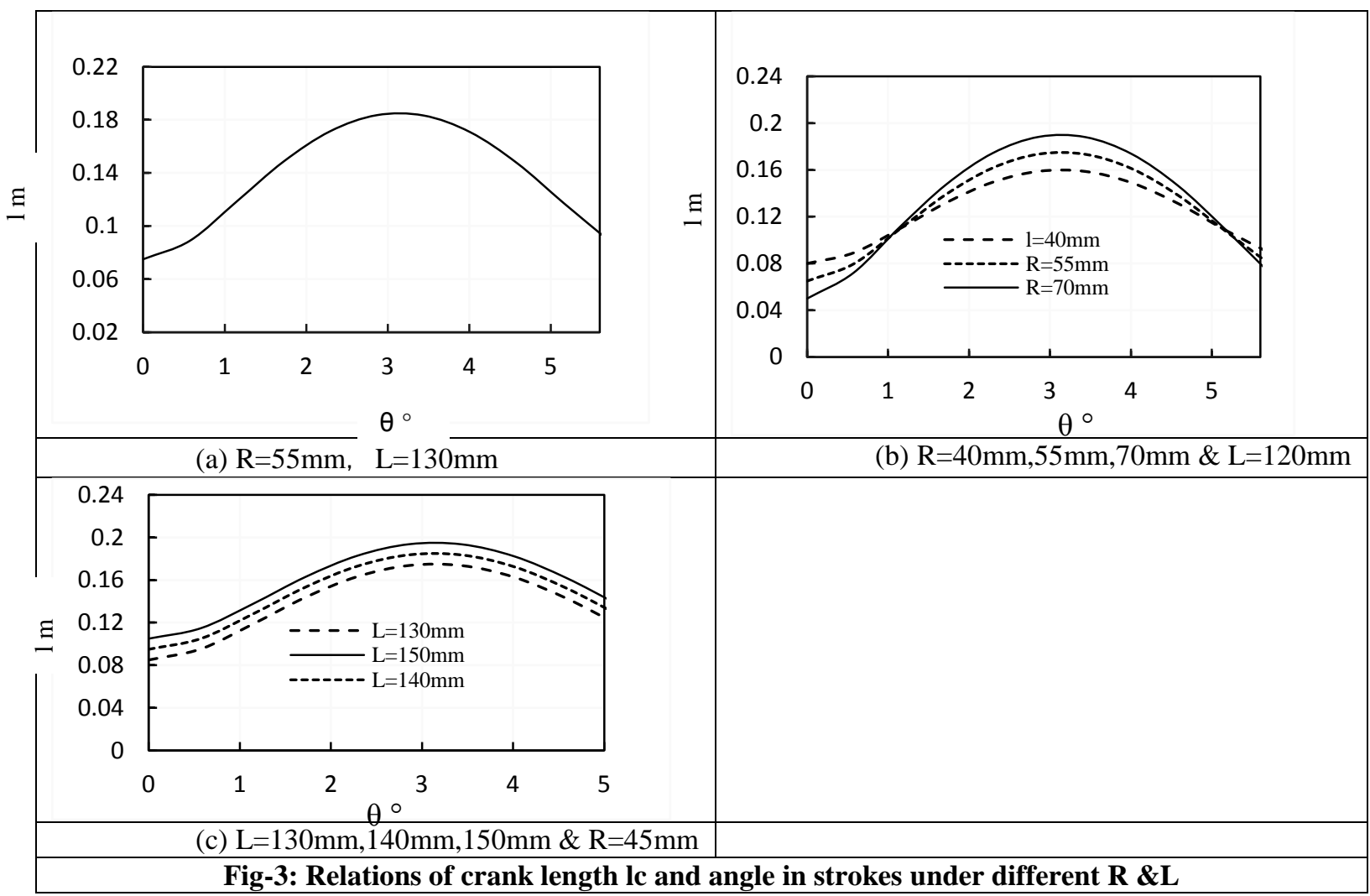


Run Xu; Saudi J Eng Technol, Nov, 2020; 5(11): 474-479

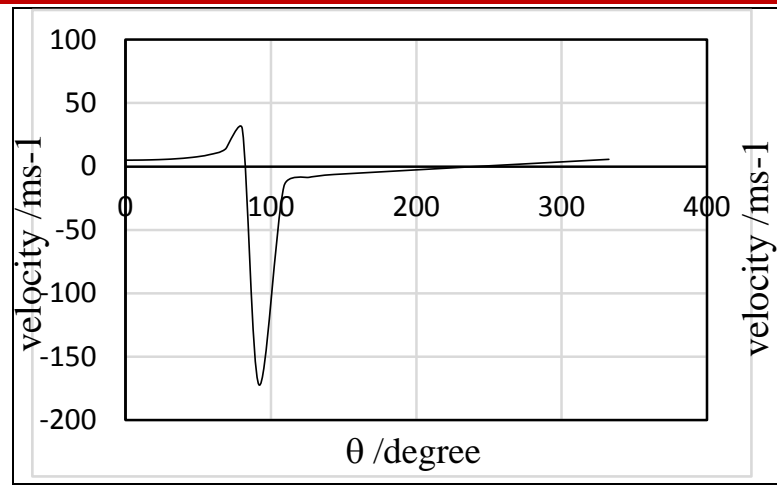

(a) $\mathrm{R}=40 \mathrm{~mm}$

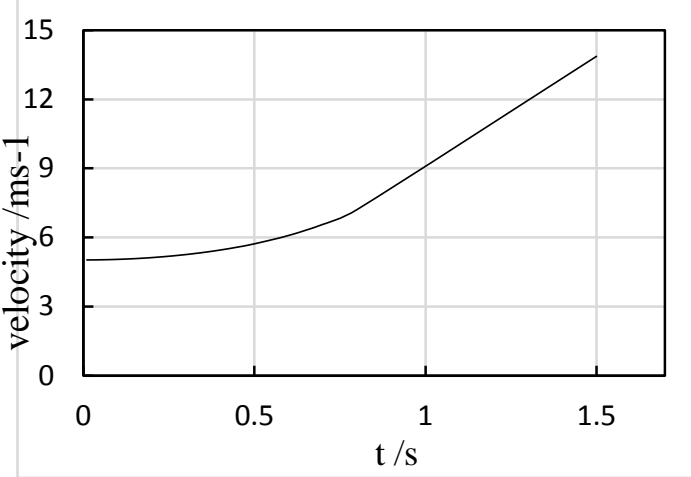

(c) $\mathrm{R}=40 \mathrm{~mm}$

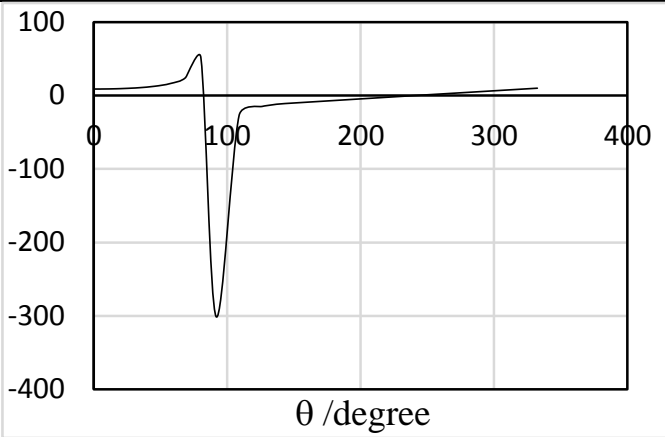

(b) $\mathrm{R}=70 \mathrm{~mm}$

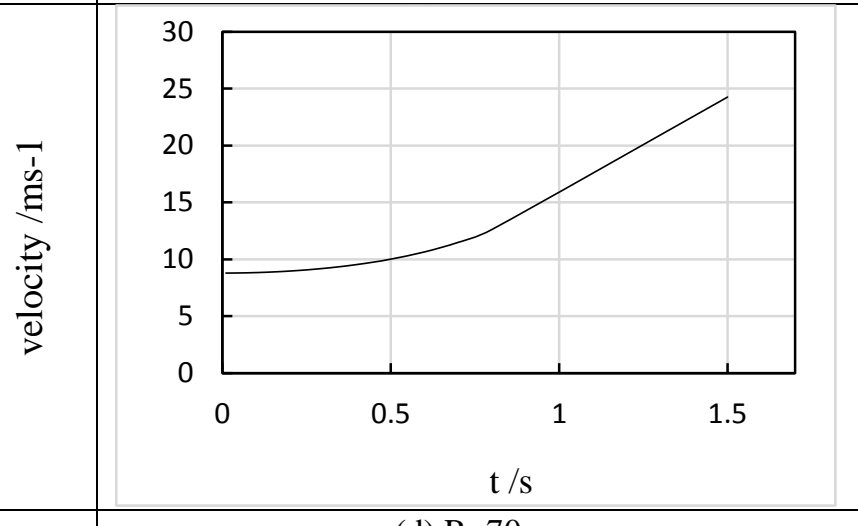

(d) $\mathrm{R}=70 \mathrm{~mm}$

Fig-4: The relations of strokes velocity and time $\&$ Sita with the parameter $R$ of a certain $\& \mathrm{n}$ of $20 \mathrm{rpm}$

Figure- 4 shows that the relations of velocity and time $\& \theta$. With increasing $\mathrm{R}$ the velocity becomes bigger, meanwhile with increasing $\mathrm{R}$ it becomes bigger too.

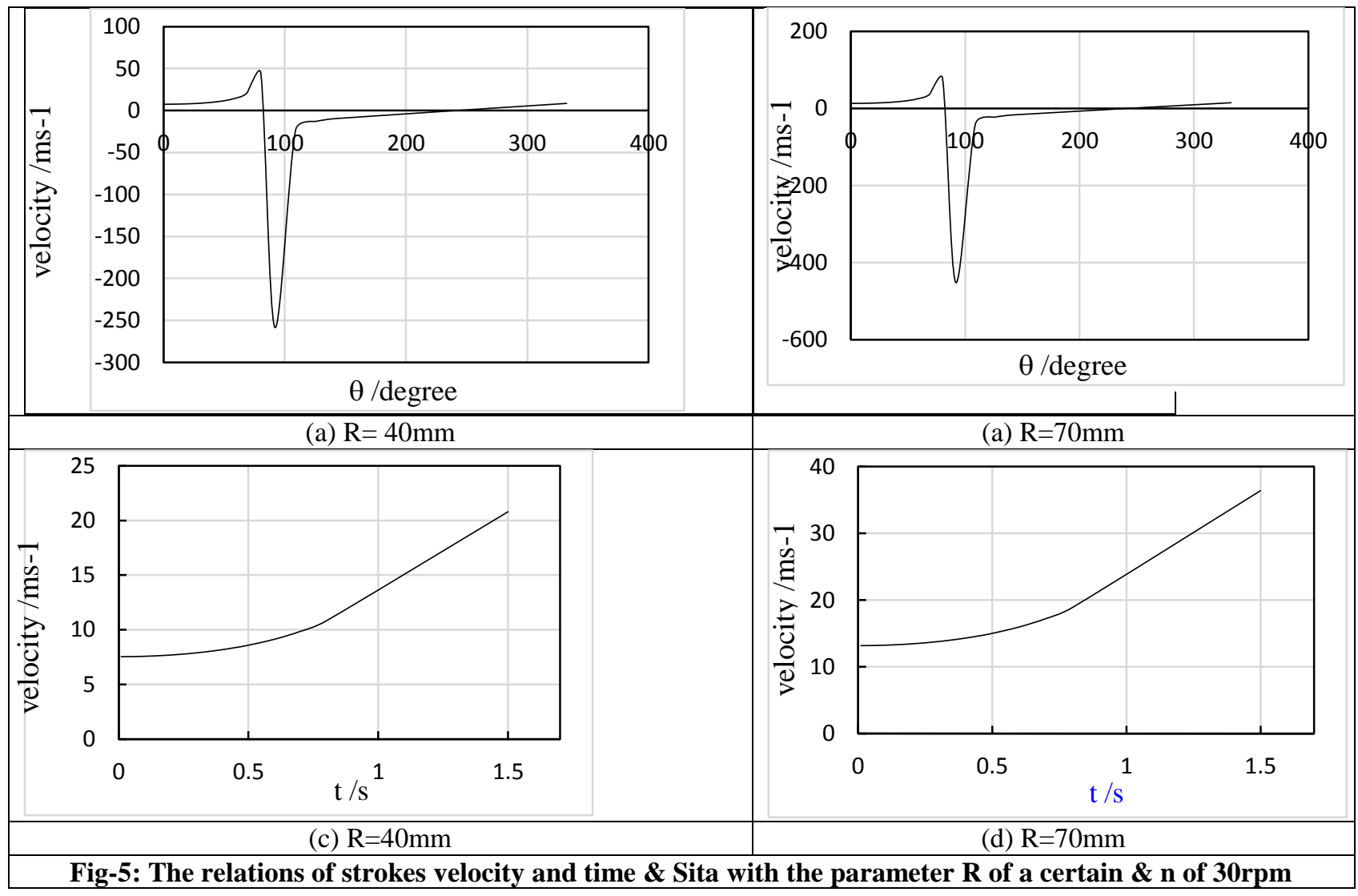




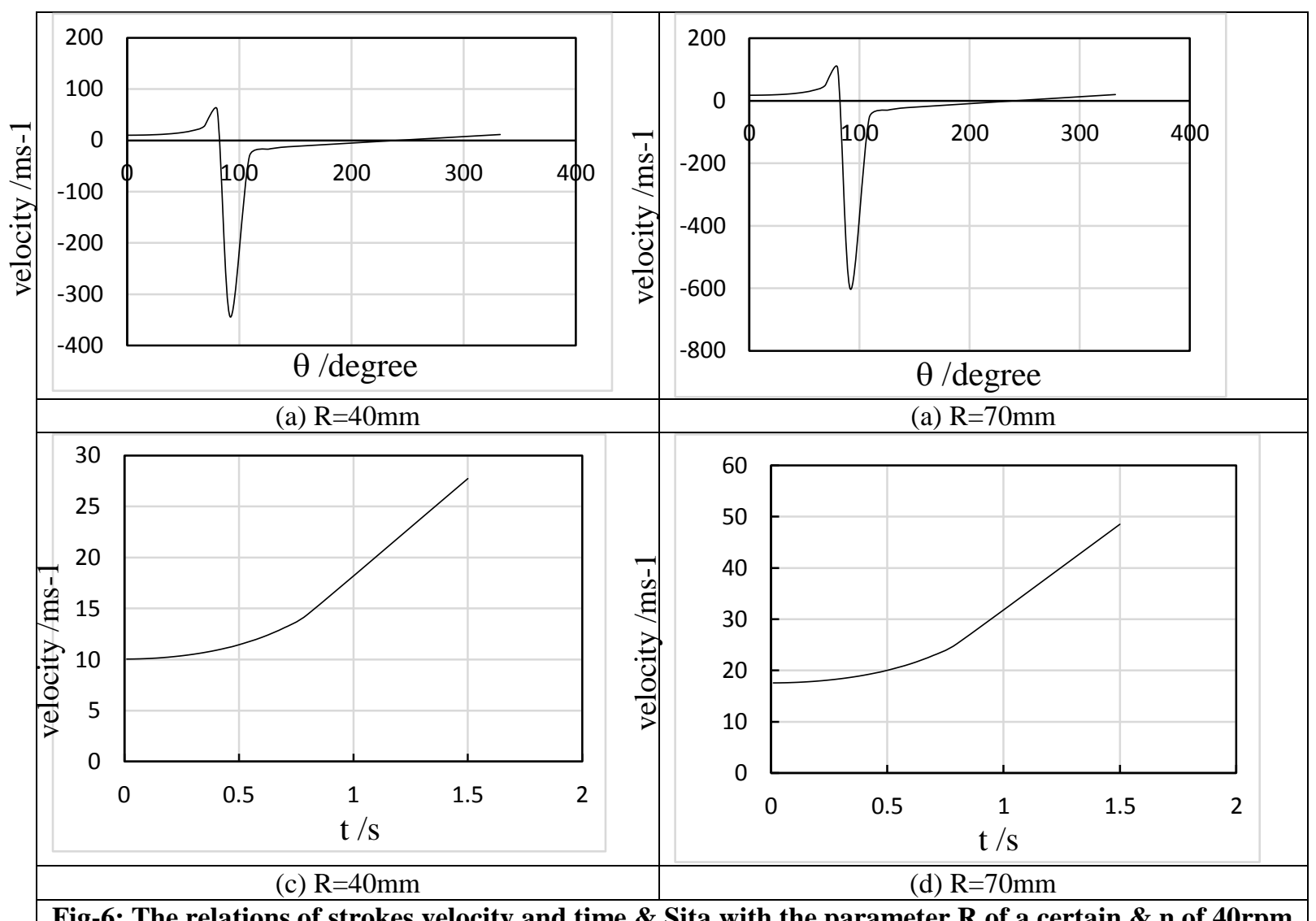

Fig-6: The relations of strokes velocity and time $\&$ Sita with the parameter $R$ of a certain $\& \mathrm{n}$ of $40 \mathrm{rpm}$
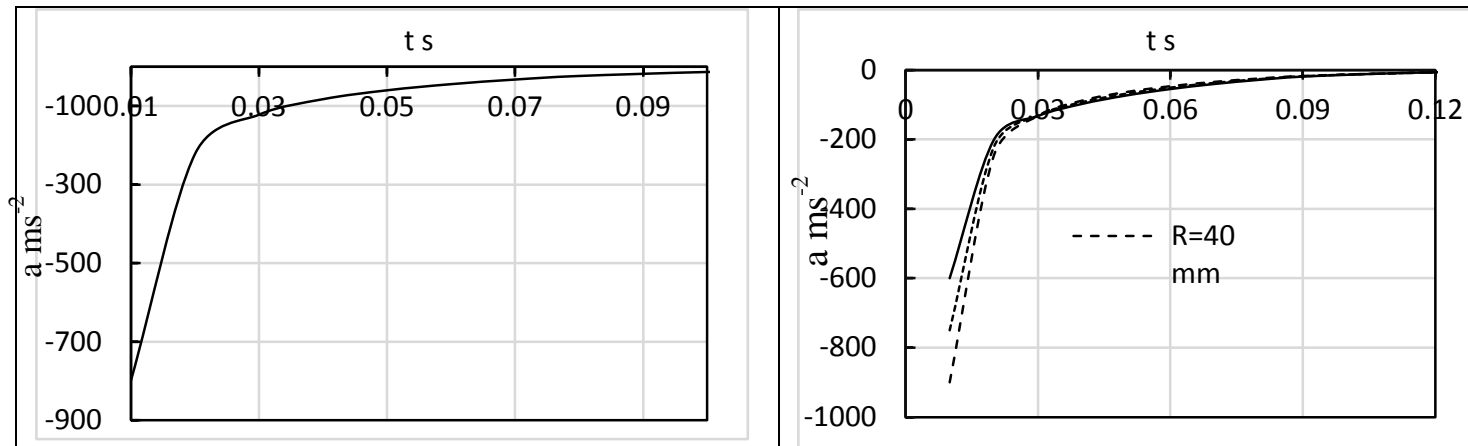

(a) $\mathrm{R}=40 \mathrm{~mm}, \quad \mathrm{~L}=120 \mathrm{~mm}$

(b) $\mathrm{R}=40 \mathrm{~mm}, \quad \mathrm{R}=55 \mathrm{~mm}, \quad \mathrm{R}=70 \mathrm{~mm} \& \mathrm{~L}=130 \mathrm{~mm}$

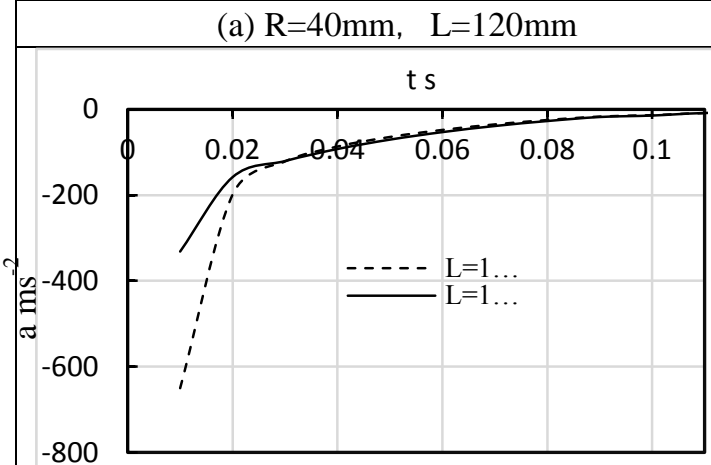

(c) $\mathrm{L}=120 \mathrm{~mm} \& \mathrm{R}=55 \mathrm{~m} ; 160 \mathrm{~mm} \& 70 \mathrm{~mm}$

Fig-7: The relations of strokes acceleration and time with the parameter $R \& L$ 
Run Xu; Saudi J Eng Technol, Nov, 2020; 5(11): 474-479

Figure-4(a) shows the data under $\mathrm{R}=45 \mathrm{~mm}$ and $\mathrm{L}=130 \mathrm{~mm}$. This indicates that the initial speed in the die is up to $500 \mathrm{~mm} / \mathrm{s}$ and the die speed decreases with the increase of time, that is, with the increase of the stamping length. If the stamping time is less than $70 \mathrm{~m} / \mathrm{s}$ in 0.2 seconds, it means that the stamping time is better than 0.3 seconds. Figure-5(a) shows that the velocity gradually decreases as time increases and finally approaches zero. The change was large before the time was 0.02 seconds, and then moderated. Figure-5(b) curves under $\mathrm{R}=45 \mathrm{~mm}$ and $\mathrm{L}=130 \mathrm{~mm}$.It indicates that the distance 1 between the mold and the center of the drive axis gradually increases with the decrease of angle from $5.4^{\circ}$, and gradually decreases after $3^{\circ}$. Figure-5(c) is at $\mathrm{L}=120 \mathrm{~mm}$, and there is no big change in the acceleration of $160 \mathrm{~mm}$. At $0.01 \sim 0.02 \mathrm{~s}$, the curve of $120 \mathrm{~mm}$ is larger than the absolute value of $160 \mathrm{~mm}$, and there is no difference after $0.02 \mathrm{~s}$. It indicates that the acceleration of the mold changes within the first $0.02 \mathrm{~s}$ when L changes.

Figure-3(b) shows the $\mathrm{L}$ change when the crank radius $R$ changes when $L=120 \mathrm{~mm}$, which is similar to Figure-5(a) in a sinusoidal curve.As $\mathrm{R}$ gets bigger and 1 gets bigger, the stroke gets bigger. When $\mathrm{R}=40 \mathrm{~mm}, 1$ is $0.07 \mathrm{~m}$, while when $\mathrm{R}=70 \mathrm{~mm}, 1$ becomes $0.12 \mathrm{~m}$. Figure-3(c) shows their curves under $\mathrm{L}=130 \mathrm{~mm}$, $140 \mathrm{~mm}, 150 \mathrm{~mm} \& \mathrm{R}=45 \mathrm{~mm}$.

\section{CONCLUSIONS}

1. With the increase of time, that is, with the increase of stamping length, the mold speed decreases gradually.Reach below $70 \mathrm{~m} / \mathrm{s}$ in 0.2 seconds.As time goes up, the velocity goes down and it goes to zero.

2. At $5.4^{\circ}$, the distance 1 between the mold and the center of the drive axis gradually increases with the decrease of Angle, and after $3^{\circ}$, the 1 gradually decreases.

3. When the crank radius $\mathrm{R}$ changes, 1 changes it shows a sinusoidal curve. As $\mathrm{R}$ gets bigger and 1 gets bigger, the stroke gets bigger.

\section{REFERENCES}

1. Run, X. (2020). Cost control with modeling in motor housing process, International Journal of Plant Engineering and Management, 25(1): 51-64.

2. Wensheng, W. (2019). Kinematics analysis of crank linkage mechanism of internal combustion engine for vehicle, Internal Combustion Engine and Accessories, 5:72

3. Run, X. (2019). The Cost Control of Motor Housing Process. International Journal of Plant Engineering and Management, 24(3):187-192.

4. Li, J., Zhao, L, Liu, S., \& Ren, S. (2008). Dynamic simulation analysis of crank linkage mechanism of type 4100 internal combustion engine, Equipment Manufacturing Technology, 12:5

5. Chao-Bo, L., \& Jing-Jun, L. (2008). Dynamic analysis of crank railing mechanism of xingxing air compressor. Chinese Ship Research. 5(13): 98.

6. Faculty of theoretical mechanics in Harbin Institute of Technology. Theoretical mechanics I [M], Higher Education Press. 2011: 267,269,272. 